\title{
Professional training of mining engineers
}

\author{
Marina A. Loshchilova ${ }^{1 *}$, Tatyana G. Trubchenko ${ }^{2}$, Elena Yu.Lemeshko ${ }^{2}$, Elena S. \\ Kiseleva $^{2}$, Elena $V$. Portnyagina ${ }^{3}$ and Sergei V.Razumnikov ${ }^{1}$ \\ ${ }^{1}$ Yurginsky Technological Institute (branch of Tomsk polytechnic university), Yurga, Russia \\ 2 National Research Tomsk Polytechnic University, Tomsk, Russia. \\ ${ }^{3}$ Omsk State Pedagogical University, Omsk, 644099, Nab. Tukhachevskogo, 14, Russia
}

\begin{abstract}
Nowadays, the solution of the problem of training mining engineers in the environment of innovation development is rather complicated and multifaceted. It involves determining the essence and content of the engineer's professional activity; the need to study the specifics of the training of a mining engineer; the requirements for training mining engineers in innovative development. It is also connected with evaluation of students' readiness level in the specialty 21.05 .04 «Mining», identifying ways to increase the level of readiness of mining engineers for professional activity. The factors influencing the results of the training of mining engineers are identified here, as well as foreign experience in the education and training of mining engineers. Besides, noncompensatory model of assessment of readiness of mining engineers for professional activity by method of threshold aggregation with example of building rating on the basis of this model is being developed.
\end{abstract}

\section{Introduction}

Today, Russian higher engineering education is rapidly developing and is subject to change due to the unity of science, education, production and the government policy. The main foundation of modern economic development is innovation [4]. At the same time, the Government of the Russian Federation is aware of the importance of the processes of modernization of enterprises and postulates the need for an innovative reorientation of the strategies of their further activities.

These provisions are based on the basic characteristics of a systematic and holistic view of the training of mining engineers in innovative development. The implementation of plans for the innovative development of our country is dictated mainly by the modernization and globalization of the economy [4].

The ongoing technological shift and the technological gap with developed countries in the face of increased competition on the world market is a challenge with a direct impact on

\footnotetext{
${ }^{*}$ Corresponding author: marisha20@bk.ru
} 
the development of our country's coal industry. Engineering personnel are responsible for the technological backwardness of the coal industry at the enterprise level. In this regard, highly qualified professionals are needed to meet the challenges of the modern world [2]. Therefore, in the context of the innovative development of the coal industry, the problem of training mining engineers seems to be very urgent and significant.

\section{Research methods}

The study presented in the article is based on the analysis of psychological and pedagogical literature, existing normative and legal documents regulating the educational process. Conceptual analysis within the framework of research of psychological-pedagogical, educational-methodical and linguistic literature was carried out for consideration of the problem of training of mining engineers.

\section{Content of professional activity of the engineer}

For a more in-depth theoretical analysis of the professional training of a mining engineer, it is necessary to characterize the modern content of his professional activity, which has changed due to the modernization and globalization of education and innovative processes in the country. For this purpose, we will identify significant signs that distinguish this activity from other types [2].

In the all-Russian classification of specialties in education the code 65 of qualification "engineer" is assigned. The study of engineering activity, its separate types are devoted to the works of N. N. Grachev, B. F. Lomov, Yu. P. Pokholkov, E. A. Shapovalov, etc.

It should be noted that the field of professional activity of engineers includes sections of science and technology, containing a set of means, techniques and methods of human activity aimed at creation of competitive products of mechanical engineering and based on application of modern methods and means of design, mathematical, physical and computer modeling of technological processes. In the context of our research, we will define engineering as a way of performing certain activities.

Summarizing the results of the analysis of theoretical studies, it should be noted that the emphasis in the definition of vocational training for mining engineers is on the personal (positive attitude of learners towards professional activity and its results, which determines stable motives) and activity component (mastery of skills, professional activity skills, ability to solve professional tasks) [5, 6].

We emphasize that the specialty «Mining» is development of the subsoil of the Earth, their study and use. The subject of the work of the mining engineer is technical facilities, materials and minerals. In the present conditions of increasing consumption of mineral raw materials and increasing needs of mankind the profession of mining engineer does not lose its relevance and becomes increasingly connected with nanotechnology and advanced computer research [4].

The Uniform tariff-qualifying directory of works and professions contains 47 occupations in the specialty of mining, among which are: the miner; the barrel digger; the driller; the underground miner; etc. According to the Federal State Educational Standards of Higher Education in the specialty "Mining" the types of professional activity of an engineer are: research; technological; organizational and managerial; design. The general professional competencies of a mining engineer include: the application of fundamental knowledge; technical design; study; integration of science and education. It should be noted that among the main areas of training at UTI TPU there is a specialty 05.21.04 "Mining". Specialty 210000 "Applied geology, mining, oil and gas and geodesy." This targeted training of specialists is carried out through the design of technical complexes and systems. Among the entrance tests: mathematics, physics and the Russian language. The term of 
study is 5 years and 6 months. Upon completion of training, the graduate receives a qualification - mining engineer [6]. Thus, having graduated from the institute in the field of mining, a graduate can work: as an engineer; a hydrologist; geologist; surveyor engineer, etc. The basis for the training of mining engineers is the development of creative and entrepreneurial components of the intellectual potential of a mining engineer, their development and balance, as well as their qualitative and quantitative assessment. An analysis of theoretical approaches to the problem of professional training of engineers indicates that many researchers, within the framework of various approaches, have contributed to the study of this problem, which allows us to consider professional training as a process of formation of general, professional and super-professional competencies [3, $4,6]$.

Thus, it is necessary to review and adjust the training system itself, applying modern approaches to the organization of the educational process, taking into account the practical orientation in the context of innovative development of the state. Let us consider how the students of the specialty 21.05.04 "Mining" (the term of study is 5 years 6 months) evaluate their level of readiness in the Jurginsky Institute of Technology (branch) of the Federal State Autonomous Educational Institution of Higher Education "National Research Tomsk Polytechnic University" (Jurga, Russia).

In order to increase the level of readiness for professional activity, mining engineers preferred: participation in scientific and practical conferences, competitions of professional excellence (40\%); attendance of seminars and round tables (22.5\%), individual consultations with teachers and masters of industrial training (17.5\%); the study of scientific and technical literature $(23.75 \%)$ and the use of information sources on the Internet $(67.5 \%)$.

On the basis of the results of the study, we present the distribution of levels of readiness of mining engineers for professional activities (table 2).

Table 1. Characterization of the distribution of levels of readiness of mining engineers (ME) for professional activities [6].

\begin{tabular}{|l|c|c|c|c|c|c|c|}
\hline \multirow{2}{*}{ Groups } & \multirow{2}{*}{$\begin{array}{c}\text { Number of } \\
\text { students }\end{array}$} & \multicolumn{6}{|c|}{ Allocated levels } \\
\cline { 3 - 8 } & & \multicolumn{2}{|c|}{ Low absolute. (\%) } & \multicolumn{2}{c|}{$\begin{array}{c}\text { Average absolute } \\
(\%)\end{array}$} & \multicolumn{2}{c|}{ High absolute (\%) } \\
\hline E-(ME) & 80 & 27 & $34 \%$ & 47 & $59 \%$ & 6 & $8 \%$ \\
\hline C-(ME) & 71 & 35 & $49 \%$ & 32 & $45 \%$ & 4 & $6 \%$ \\
\hline
\end{tabular}

Analysis of the obtained empirical data showed that a large proportion of students in the E- (ME) experimental group (34\%) had a low (45.25\%) or medium (48.5\%) level of readiness for professional activity. The $\mathrm{C}$-(ME) control group had a low level of $48.5 \%$, an average level of $44 \%$ and a high level of $7.5 \%$. This was reflected in the lack of motivation for training, the insufficient desire to improve the way of carrying out professional activities, the lack of understanding among students of the need for self-realization in various types of professional activities, the lack of activity in technical and scientific creativity and passive participation in various projects together with social partners.

It seems necessary to identify the factors affecting the performance of training of mining engineers. External factors affecting the training of mining engineers are as follows: 
- the socio-economic situation in the country, which determines the modernization and globalization of vocational education and the need to study the labor market as an indicator of the national welfare, stability;

- innovative achievements of science and practice, defining guidelines and modern requirements for the content of professional activities of mining engineers; a system of continuing professional education;

- social partnership, which is one of the conditions for the development of open educational systems [6].

World practice has shown that a practical approach is the most appropriate way to train effectively mining engineers. There is an interesting experience of teaching and training in the United States of America and other European countries with a multi-level system of mountain education: Bachelor - Master - Phd [9, 10].

The mining curriculum (Mining) is multidisciplinary and covers various aspects of geology, physics, chemistry, ecology, mathematics and economics. Students study mineral discovery and mining technologies, as well as related management and environmental sciences. In addition, mining engineers study geomechanics, ventilation, mining planning and mineral processing. Most mining engineering courses consist of mandatory and elective modules, allowing students to achieve individual academic goals. In addition, many programs have an extensive practical component that helps to put the theoretical knowledge into practice and to establish the necessary professional contacts. Some courses also involve laboratory work. [9-11].

Since mining is a classical engineering specialty, the curricula in this field are mostly standard and not very diverse [7-10]. Colorado Universities of Australia, where many vacancies are available for mountain engineers such as the University of New South Wales and the University of Queensland, offer advanced programs that can combine the study of mining engineering and the study of other disciplines such as economics, commerce, business, physics, computer software, chemistry, climate dynamics, geology, biotechnology, Earth sciences, anthropology and archaeology [11-13].

Internal factors influencing the training of mining engineers: values and norms that determine the attitude to professional activity; professional needs of mining engineers and Personal qualities; subject position of mining engineers [6]. We will consider the identified factors in the design and implementation of the pedagogical model of professional training of mining engineers in the conditions of innovative development.

\section{Non-compensatory model of assessment of readiness of mining engineers by threshold aggregation method. Creation of the aggregated rating}

When assessing the level of readiness of mining engineers, it is important to take into account the criteria of readiness developed by us: positive attitude to professional activity and motivation to train in technical higher education; managerial skills and skills; design and skills; skills to solve professional tasks.

Low scores for one criterion are not allowed to be offset by high or average scores for other criteria [1].

In order to solve such problems in the work, it is proposed to build an aggregated rating, which is based on the application of the threshold aggregation rule and is used in multicriteria evaluation tasks.

The main characteristic of the proposed rule is its uncompensatory nature, which is that it is impossible to compensate for the low value of one of the criteria with higher values for other criteria. Threshold aggregation rule and rating index. Let A be a finite set of alternatives that are evaluated by $n$ criteria. In our task of building an aggregated rating of 
mountain engineers, the alternatives will be specific graduate students of the race specialty [8].

The Expert Commission considered 80 participants (mountain engineers) for evaluation. The evaluation was conducted on a five-degree scale (Table 1) based on questionnaire and testing.

Table 2. Five-degree rating scale of providers [8].

\begin{tabular}{|c|c|c|}
\hline Assessment & Point & Description \\
\hline Excellent & 5 & The score is very high, almost ideal \\
\hline Good & 4 & The score is very high, but not ideal \\
\hline Satisfactory & 3 & Score above minimum but not best \\
\hline Satisfactory & 2 & $\begin{array}{c}\text { Indicator at minimum satisfactory level, meets } \\
\text { minimum standards }\end{array}$ \\
\hline Unsatisfactory & 1 & Low, below minimum standards \\
\hline
\end{tabular}

Each alternative $\mathrm{x}$ of $\mathrm{A}$ is set in accordance with the vector $\left(x_{1}, \ldots, x_{n}\right)$, where $x_{i}$ - the rank of mining engineer according to the corresponding criterion $i$, i.e. $x_{i} \in\{1, \ldots, 5\}$, $i=1, . ., n$.

The challenge is, on the basis of the given by the expert commission estimates $\left(x_{l}, \ldots\right.$, $x_{n}$ ) for all alternatives of $x$ to rank set $\mathrm{A}, \mathrm{i}$. e. for each engineer to find his sequence number in the aggregate ranking list.

For each $x_{j} \in A$ we write $x=\left(x_{1}, \ldots, x_{n}\right)$. Therefore, A will consist of all possible $\mathrm{n}$ dimensional vectors of the form $\left(x_{1}, \ldots, x_{n}\right)$.

To achieve this, the threshold rule [1] is applied and the index is calculated using the threshold assessment method.

The threshold aggregation rule is that first the number of units are compared, i. e. the number of ratings «unsatisfactory», («bad») in the vectors $\mathrm{x}$ and $\mathrm{y}$. If they are not equal the variant (vector) with fewer units (worst ratings) is preferable. If in $\mathrm{x}$ and $\mathrm{y}$ the number of units is equal, then the number of average estimates (number of 2) is compared. The option with less will be considered preferable, etc. If the number of all grades is equal (unit, 2, 3, etc.), then these vectors are considered equal and incomparable. That is, if the poor scores are equal, the best is the one with the lower averages. $x \in A$.

According to the threshold aggregation rule, the index of the alternative will be the sum of the numbers of combinations from a to $b(1)$ :

$$
F(x)=\sum_{j=1}^{m} C_{a(j)}^{b(j)},
$$

where the number of combinations is defined: $C_{-1}^{0}=1$, and $C_{n}^{n+1}=0$.

$a$ and $b$ depend on $\mathrm{j}$ and are defined as (2), (3):

$$
\begin{gathered}
a(j)=n-V_{j}(x)+m-j-1 \\
b(j)=m-j ;(3)
\end{gathered}
$$

$V_{j}(x)$ is defined as a sum: $V_{j}(x)=\sum_{q=1}^{j} \eta(q)$ and $\sum_{j=1}^{m} V_{j}(x)=n$.

$\eta(q)$ is defined as the number of parameters by which this alternative has value $q$ ( $q$ : gradation from 1 to $\mathrm{m})$.

After finding the number of combinations $\mathrm{a}$ by $\mathrm{b}$, find $\mathrm{C}$ by combinatorics formula 


$$
C_{a}^{b}=\frac{a !}{b !(a-b) !}
$$

The preference function $\mathrm{F}$ in explicit form (for $m \geq 4$ ) is represented in the works [1]. As a result of the substitution (2) and (3) in (1) a combinatorial formula (5) is obtained:

$$
F(x)=\sum_{j=1}^{m} C_{n-V_{j}(x)+m-j-1}^{m-j}=\sum_{j=1}^{m} C_{n-(\eta(1)+\eta(2)+\ldots+\eta(j))+m-j-1}^{m-j}
$$

Within the rating model of mining service engineers here $n$ - the number of criteria for evaluation, $m=5$ is the number of gradations (estimates). In our case, $1,2,3,4,5 . V_{j}(x)$ - the number of estimates $j$ at the provider $\mathrm{x}$. The function $F(x)$ takes a natural value on any vector $x$ equal to the ordinal number of that vector in the strict preference described above. The $F$ function has optimal properties such as Pareto-dominations, symmetry, etc.

The normalized threshold aggregation preference index will be:

$$
I_{\text {Threshold }}=\frac{F}{F_{\max }},(6)
$$

$F_{\text {max }}$ - is the maximum value of the preference index. The normalized index varies from 0 to 1 , and accordingly the higher the index value, the higher the estimate will be.

We will build an aggregated rating by threshold aggregation method. To consider the example, take 10 graduates and evaluate the readiness according to the proposed model.

For identification of mining engineers are assigned numbers from 1 to 10 according to the number of considered list. Since the indicators are qualitative, expert evaluations on the

\begin{tabular}{|c|c|c|c|c|}
\hline \multirow[b]{2}{*}{$\begin{array}{c}\text { Mining } \\
\text { engineers }\end{array}$} & \multicolumn{4}{|c|}{ Assessment criteria } \\
\hline & $\begin{array}{l}\text { Positive attitude to } \\
\text { professional activity } \\
\text { and motivation to study } \\
\text { at a technical university }\end{array}$ & $\begin{array}{l}\text { Management } \\
\text { skills and } \\
\text { competencies }\end{array}$ & $\begin{array}{l}\text { Engineering and } \\
\text { designing skills }\end{array}$ & $\begin{array}{l}\text { Ability to perform } \\
\text { professional tasks }\end{array}$ \\
\hline Student 1 & 5 & 2 & 4 & 4 \\
\hline Student 2 & 5 & 5 & 5 & 5 \\
\hline Student 3 & 4 & 3 & 5 & 3 \\
\hline Student 4 & 3 & 5 & 2 & 5 \\
\hline Student 5 & 4 & 4 & 4 & 4 \\
\hline Student 6 & 4 & 2 & 5 & 4 \\
\hline Student 7 & 5 & 5 & 3 & 5 \\
\hline Student 8 & 4 & 5 & 3 & 3 \\
\hline Student 9 & 3 & 3 & 3 & 5 \\
\hline Student 10 & 5 & 4 & 4 & 4 \\
\hline
\end{tabular}
scale are applicable at once (Table 2) and we record them in Table 3.

Table 3. Criteria scores for the providers under review [8].

We will illustrate the position of vectors in the rating according to their scores presented in Table 2 for our version, using the non-compensatory rating method discussed above. 


$$
\begin{gathered}
(2,3,5,5)_{1}^{4}, \quad(2,4,4,5)_{2}^{1}, \quad(2,4,4,5)_{3}^{6}, \quad(2,3,3,4)_{4}^{9}, \quad(3,3,4,5)_{5}^{3}, \quad(3,3,4,5)_{6}^{8}, \quad(3,5,5,5)_{7}^{7}, \\
(4,4,4,4)_{8}^{5}, \quad(4,4,4,5)_{9}^{10},(5,5,5,5)_{10}^{2}
\end{gathered}
$$

The lower index on the right indicates the sequence number of the vector in the rating. The upper index on the right indicates the provider's sequence number in table 2 . Now calculate the preference index by formula (5). Consider an example of how to calculate the maximum value of the index.

For the number of parameters $n=4$, and the number of gradations $m=5$, find the index of the best alternative, i. e. alternative, which has all values $=5$.

$$
\begin{aligned}
& \eta(1)=\eta(2)=\eta(3)=\eta(4)=0 ; \eta(5)=4 ; \\
& V(1)=V(2)=V(3)==V(4)=0 ; V(5)=4 ; \\
& \mathrm{a}(1)=\mathrm{n}-V(1)+\mathrm{m}-\mathrm{j}-1=4-0+5-1-1=7 ; \mathrm{a}(2)=4-0+5-2-1=6 ; \mathrm{a}(3)=4-0 \\
& +5-3-1=5 ; \\
& \mathrm{a}(4)=4-0+5-4-1=4 ; \mathrm{a}(5)=4-4+5-5-1=-1 ; \\
& \mathrm{b}(1)=\mathrm{m}-1=5-1=4 ; \mathrm{b}(2)=5-2=3 ; \mathrm{b}(3)=5-3=2 ; \mathrm{b}(4)=5-4=1 ; \mathrm{b}(5)=5-5=0 ; \\
& \quad \text { Index of the best alternative: } \\
& \quad \mathrm{F}_{\max }=\mathrm{C}_{7}^{4}+\mathrm{C}_{6}^{3}+\mathrm{C}_{5}^{2}+\mathrm{C}_{4}^{1}+\mathrm{C}_{-1}^{0} .
\end{aligned}
$$

Let us give a detailed example of the calculation of the ratio by formula (4).

$$
C_{7}^{4}=\frac{7 !}{4 !(7-4) !}=\frac{4 ! \times 5 \times 6 \times 7}{4 ! \times 3 !}=\frac{210}{6}=35
$$

So, $F_{\max }=35+20+10+4+1=70$.

i.e. the maximum index value: 70 .

We will now calculate the preference index for the mining engineer with the worst estimates, having the order number 1 in the rating.

$$
\begin{aligned}
& \quad \eta(1)=0 ; \eta(2)=1 ; \eta(3)=1 ; \eta(4)=0 ; \eta(5)=2 ; \\
& \quad V(1)=0 ; V(2)=1 ; V(3)=2 ; V(4)=2 ; V(5)=4 \\
& \quad \mathrm{a}(1)=\mathrm{n}-V(1)+\mathrm{m}-\mathrm{j}-1=4-0+5-1-1=7 ; \mathrm{a}(2)=4-1+5-2-1=5 ; \mathrm{a}(3)=4-2 \\
& +5-3-1=3 ; \\
& \mathrm{a}(4)=4-2+5-4-1=2 ; \mathrm{a}(5)=4-4+5-5-1=-1 ;
\end{aligned}
$$

The values $b(1-5)$ will be the same.

Index for alternative with order number 1 in rating:

$$
\mathrm{F}_{1}=\mathrm{C}_{7}^{4}+\mathrm{C}_{5}^{3}+\mathrm{C}_{3}^{2}+\mathrm{C}_{2}^{1}+\mathrm{C}_{-1}^{0}=35+10+3+2+1=51
$$

Then the normalized value according to the formula (6)

$$
I_{1}=\frac{51}{70}=0,729
$$

Similarly, we will calculate the other indexes, find the normalized values, and record the results.

Based on the calculations made by the threshold aggregation method, the best mining preparation engineer is a Student 1 graduate with a preference function value of 70 . The worst under consideration is Student 4 with a value of -51 . Please note that students 8 and 3 scored the same number of points, respectively they divide the 5th place in the rating, as well as students 1 and 6 divide the 7th place [8].

Thus, this model allowed to estimate the level of readiness of mining engineers in quantitative equivalent, and also allowed to identify the best in the rating. Such a rating can be used, for example, in encouraging a graduate, or to identify the best student in a competition, or to recommend to employers.

\section{Results}


Summarizing the findings of the theoretical and practical study on the mining engineers' training for professional activities, we will highlight the main results. Basic terms defining the process of preparing mining engineers for professional activity have been reviewed and clarified.

«Professional training of mining engineers» is defined as a holistic and dynamic process, which includes the formation of general cultural, professional competences and soft skills, ensuring that mining engineers are ready for scientific research, design and development, organization and management, production and technological activity.

Features of multi-level system of training of engineers for modern production industry have been identified. The content of mining education and its level are determined by the requirements of mining production and are determined by social relations and the state of science, technology and culture.

It has been determined that a number of criteria must be taken into consideration for the evaluation of the engineering training effectiveness: the structure of the curricula and the ratio of basic part to vocational training; the role of industrial training in the curricula and the bases for their completion; level of implementation of project training.

A vocational training model for mining engineers has been developed and implemented to assess the level of readiness of mining engineers in quantitative terms and to identify the best students in the ranking (encouragement of graduates, identification of the best student in the competition, for recommendations to employers and social partners), creation of a single informational and educational space, organization of the process of personal and professional development of the trainees. This model can be adapted to any engineering school.

\section{Conclusion}

Thus, a number of conclusions can be drawn from the analysis of the issue of mining engineers' training.

1. Public-private partnerships through networking among education, production and science are needed to ensure the effective training of mining engineers and their relevance and innovation. In our view, it is necessary to adjust the system of mining engineers' training to the practical-oriented direction and modern approaches in the context of the state innovative development.

2.Universities that train future engineers must remain competitive (the emergence of small, innovative enterprises, intellectual research, etc.)

3.Important areas of training for mining engineers in the context of innovative development are:

-The development of innovative thinking and entrepreneurship;

-Improvement of educational standards, programmes with a project-oriented approach, and innovative disciplines, with the possibility of developing and protecting the startups upon completion of their studies.

-Organization of further training and retraining of personnel in the field of new innovative technologies, entrepreneurship and management.

The results of the research can be used in educational organizations of vocational education to train future engineers.

There ported study was funded by RFBR, project number 19-29-07350.

\section{References}

1. F. Aleskerov. The threshold aggregation, Econ. lett. 107(2), 161-162 (2010) 
2. P. R. Atutov. Polytechnic education in the conditions of integration of science and production, Soviet pedagogy, 4, 35-40 (1991)

3. S. A. Borisenkova. Professional training of competitive specialists in the field of Economics. Diss. ... candidate of pedagogical Sciences. Komsomolsk-on-Amur, 180 p. (2004).

4. A.A. Rozhkov, I.S. Solovenko, T.A. Korkina, M.A. Loshchilova, Engineering and technical composition of the coal industry in Russia: a retrospective, current state, forecast, Coal, 4. 16-25 DOI: 10.18796/0041-5790-2020-4-16-25. (2020)

5. E.S. Kiseleva et al., The psychological portrait as a tool to improve the subjective wellbeing of the client in the context of personal sales, SHS Web of Conferences, 28 (2016)

6. M.A. Loshchilova, V.G. Lizunkov, A. Zavyalova. Professional Training of Bachelors in Mechanical Engineering, Based on Networking Resources, Procedia - Social and Behavioral Sciences, 206, 399-405 (2015)

7. L.F. Mikhaltsova, O.A Milinis, N.A. Danichkina, Loshchilova M.A. Innovative strategy of educational space for creative self-development and competitiveness of future specialists, Italian Science Review, 10(2), 31-36 (2014)

8. S.V Razumnikov, A.K. Kurmanbay. Models of evaluating efficiency and risks on integration of cloud-base IT-services of the machine-building enterprise: a system approach, IOP Conference Series: Materials Science and Engineering, 124, 012089 (2020)

9. T. Josefsson. Intercultural Competence in Engineering Education, CDIO Knowledge Library. Cambridge, MA; Worldwide CDIO Initiative. URL: http://www. cdio.org/files/document/file/T2A_Paper_2.pdf (11.02.2020).

10. AGH University of Science and Technology: URL:http://www.agh.edu.pl/ (date of the request 15.02.2020).

11. South Dakota School of Mines and Technology: URL:http://www.sdsmt.edu/ (date of the request 20.11.2019).

12. University of Arizona: URL:http://www.arizona.edu/ (date of the request 21.02.2020).

13. University of Kentucky: URL:http://www.uky.edu/UKHome/ (date of the request 25.02.2020). 